\title{
Domestic ships as a potential pathway of nonindigenous species from the Saint Lawrence River to the Great Lakes
}

\author{
Abisola A. Adebayo - Aibin Zhan • \\ Sarah A. Bailey $\cdot$ Hugh J. MacIsaac
}

Received: 24 January 2013/ Accepted: 20 August 2013/Published online: 13 September 2013

(C) Springer Science+Business Media Dordrecht 2013

\begin{abstract}
Ballast water moved by transoceanic vessels has been recognized globally as a predominant vector for the introduction of aquatic nonindigenous species (NIS). In contrast, domestic ships operating within confined geographic areas have been viewed as low risk for invasions, and are exempt from regulation in consequence. We examined if the St. Lawrence River could serve as a source of NIS for the Laurentian Great Lakes by surveying ballast water carried by domestic vessels and comparing biological composition in predominant St. Lawrence River-Great Lakes port-pairs in order to determine the likelihood that NIS could be transported to, and survive in, the Great Lakes. Thirteen potential invaders were sampled from ballast water, while 26 taxa sampled from St. Lawrence River ports are not reported from the Great Lakes. The majority of NIS recorded in samples are marine species with low potential for survival in the Great Lakes, however two euryhaline species (copepod Oithona
\end{abstract}

Electronic supplementary material The online version of this article (doi:10.1007/s10530-013-0537-5) contains supplementary material, which is available to authorized users.

A. A. Adebayo · A. Zhan · H. J. MacIsaac $(\bowtie)$

Great Lakes Institute for Environmental Research, University of Windsor, Windsor, ON N9B 3P4, Canada e-mail: hughm@uwindsor.ca

\section{S. A. Bailey}

Great Lakes Laboratory for Fisheries and Aquatic Sciences, Fisheries and Oceans Canada, Burlington, ON L7R 4A6, Canada similis, and amphipod Gammarus palustris) and two taxa reported from brackish waters (copepod Microsetella norvegica and decapod Cancer irroratus) may pose a risk for invasion. In addition, four marine NIS were collected in freshwater samples indicating that at least a subset of marine species have potential as new invaders to the Great Lakes. Based on results from this study, the ports of Montreal, Sorel, Tracy and Trois Rivières appear to pose the highest risk for new ballastmediated NIS from the St. Lawrence River to the Great Lakes.

Keywords Alien species - Nonindigenous species · Invasive species · Great Lakes · Saint Lawrence River · Community composition

\section{Introduction}

The anthropogenic movement of nonindigenous species (NIS) around the world has occurred for many centuries, though the rate of invasions accelerated in recent decades owing to technological advances in transportation, expanding global economies, and attendant international trade (e.g. Mack et al. 2000; Work et al. 2005; Hulme 2009; Sylvester and MacIsaac 2010). Dispersal of NIS is strongly shaped by, and reflects movement of, transport vectors that facilitate global commerce and travel. Transoceanic ships have been a dominant vector of aquatic NIS, with ballast water, ballast sediments and hull biofouling attributed 
with introduction of hundreds of species globally (Ruiz et al. 1997; Minchin and Gollasch 2003; Bailey et al. 2007).

Vector management seeks to reduce the diversity and abundance of NIS transported to new locations (Lodge et al. 2006; Ricciardi 2006; Bailey et al. 2011a). In order to reduce invasions by ballast water, a number of countries require foreign vessels to manage ballast water by mid-ocean ballast water exchange (USCG 1998; Government of Canada 2006). Midocean exchange reduces the abundance of NIS in ballast tanks through purging of biota at sea, and is particularly protective of freshwater ports through the introduction of a salinity barrier that imposes osmotic stress on freshwater NIS (Bailey et al. 2011a; Briski et al. 2013).

Ballast discharges by domestic vessels operating within the exclusive economic zone of a single country are currently exempted from regulation, despite evidence of their importance in the spread of NIS between ports (Lawrence and Cordell 2010; Briski et al. 2012b). General assumptions that regional ports within "common waters" have contiguous communities have also been called into question (Lawrence and Cordell 2010; David et al. 2013). As an example, ballast water transfers from ports on the St. Lawrence River into the Great Lakes may seem benign since the two regions are naturally connected, however, this large geographic region has distinct ecoregions with diverse biological communities where species native to one location may be nonindigenous elsewhere (Briski et al. 2012b). Ports on the Saint Lawrence River are also visited by transoceanic and coastal ships, linking Saint Lawrence River ports to more than 75 different ballast source ports in coastal North America, South America, Europe and Africa, presenting the possibility of 'stepping stone' invasions mediated by domestic ballast transfers to the Great Lakes (Rup et al. 2010; Bailey et al. 2011b). In fact, the Great Lakes currently support 22 NIS that are either native to, or were first reported in, the Saint Lawrence River or other North American east coast rivers, suggesting that Saint Lawrence River ports may be an important source for NIS introductions to the Great Lakes (de Lafontaine and Costan 2002; Kelly et al. 2009; Bailey et al. 2011b).

Depending on their configuration, domestic vessels are capable of hauling up to 70,000 tonnes of cargo per trip, with an average trip taking 3-4 days between ports on the Great Lakes (Rup et al. 2010). Survival of plankton in ballast water during short transits of domestic vessels tends to be higher than that of many oceanic voyages, which can take one to several weeks (Simkanin et al. 2009, Lawrence and Cordell 2010). However, as the Saint Lawrence River has fresh, brackish and euhaline ports, uncertainty exists regarding survival of Saint Lawrence River species discharged into the Great Lakes. We expect that survival will be lowest for euhaline to freshwater movements; notwithstanding this, there are precedents of euryhaline species invading the Great Lakes (Ricciardi and MacIsaac 2000; Kelly et al. 2006; Rup et al. 2010), indicating a need for investigation of Saint Lawrence River to Great Lakes ballast water movements.

Here we explore the role of Saint Lawrence River ballast water as a vector of NIS dispersal to the Great Lakes. We surveyed Saint Lawrence River ballast water carried by domestic vessels to ports on the Great Lakes and compared biological composition in predominant Saint Lawrence River-Great Lakes portpairs in order to determine the likelihood that NIS from the Saint Lawrence River could be transported to, and survive in, the Great Lakes.

\section{Materials and methods}

Sampling strategy

We collected ballast water samples from domestic vessel transits between the Saint Lawrence River and the Great Lakes. We also collected zooplankton and zoobenthos samples from Saint Lawrence River ports that serve as sources of domestic ballast water, as well as Great Lakes ports where Saint Lawrence River ballast is discharged (Rup et al. 2010) (Fig. 1). St. Lawrence River ports were assigned risk categories based on the amount of ballast each port sourced to the Great Lakes between 2005 and 2007, and on port salinity. The natural break in a scatter plot of total volume of Great Lakes-bound, Saint Lawrence River ballast moved by domestic ships over the 3 year period of 2005-2007 was used to assign Saint Lawrence River ports into a high or low ballast activity group. The high volume group consisted of ports (Québec City, Sorel, Montreal, Port Cartier, and Baie Comeau) that sourced more than 35,000 tonnes of ballast to the Great Lakes, while the low volume 
Fig. 1 Location of ports sampled in the (a) Saint Lawrence River and (b) Great Lakes. Port marker in panel (a) reflects assigned risk categories: black dotshigh risk; open dotsmedium risk; open dot with a diagonal line-low risk.

The dotted line in both panels indicates the separation of the Great Lakes proper and the Saint Lawrence River
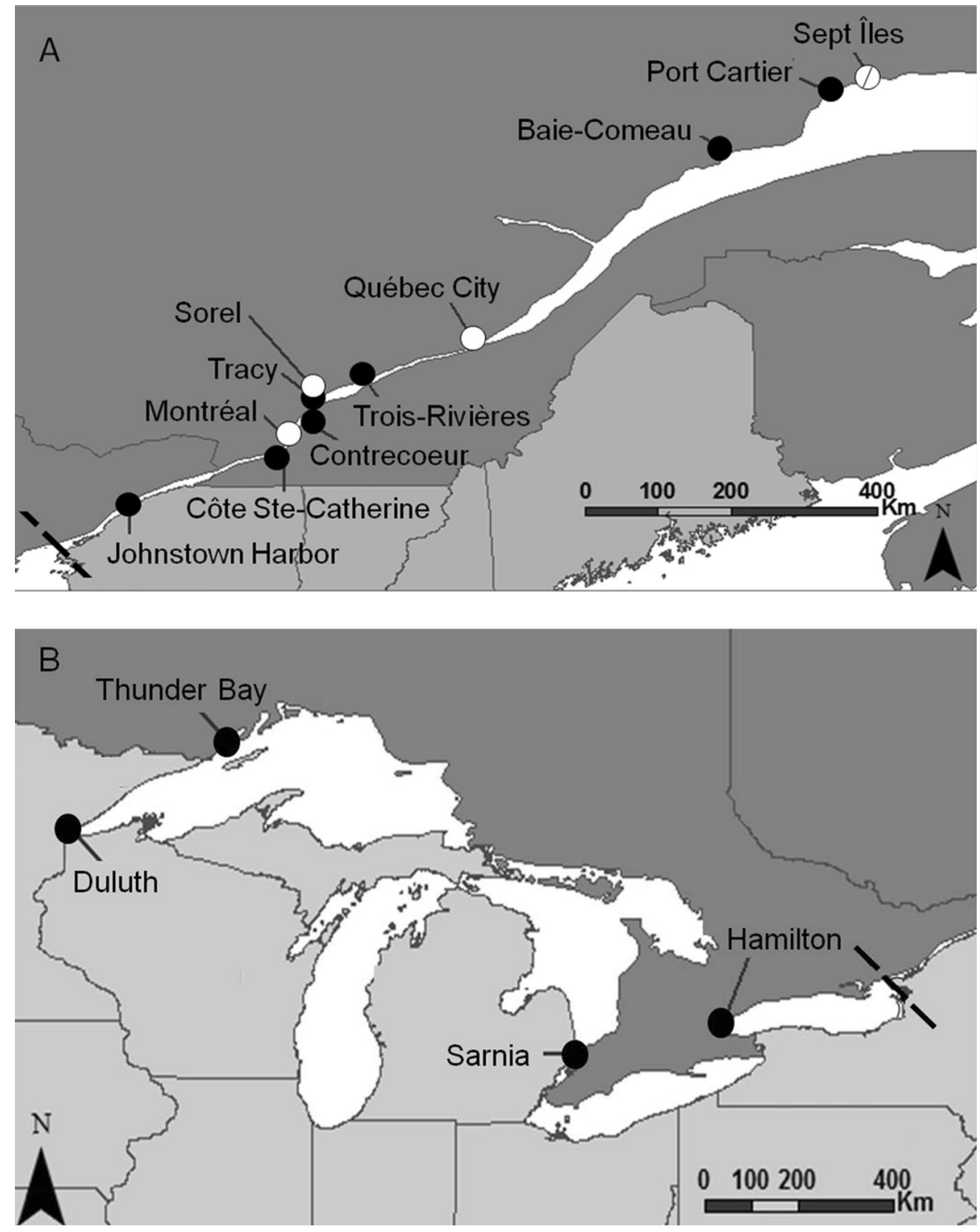

group (Côte Ste Catherine, Johnstown Harbour, Contrecoeur, Tracy, Trois Rivières, and Sept Îles) each donated less than 35,000 tonnes. Next, ports were classified as fresh $(0-0.5 \mathrm{ppt})$ or marine $(>17 \mathrm{ppt})$, with the three ports downstream of Québec City designated marine (Baie Comeau, Port Cartier, and Sept Iles) and the remaining seven upstream ports designated freshwater (Vincent and Dodson 1999). Three risk categories were thus created for Saint Lawrence River ports that sourced ballast to the Great Lakes: high risk ports involved high volumes of freshwater (Montréal, Québec City, Sorel); medium risk ports involved a low volume of freshwater (Côte
Ste Catherine, Contrecoeur, Johnstown Harbour, Trois Rivières, Tracy) or high volume of marine water (Port Cartier, Baie Comeau); and low risk ports involved low volume of marine water (Sept Îles) (Fig. 1a).

We collected ballast water samples from 30 vessels bound for the Great Lakes that carried Saint Lawrence River ballast between May 2007 and October 2010. Nineteen of these samples were freshwater ballast $(<0.5 \mathrm{ppt}), 10$ samples were marine ( $>17 \mathrm{ppt})$, and one was sourced from a freshwater port but appeared to be mixed with a significant volume of residual marine water (3.6 ppt). Twenty-nine samples were collected by repeatedly lowering a $53 \mu \mathrm{m}$ vertical zooplankton 
net to a depth of $2-15 \mathrm{~m}$ in a single location (ballast tank) until approximately $1,000 \mathrm{~L}$ of water was filtered. One sample was collected by pumping $50 \mathrm{~L}$ of ballast water from a single tank through a sounding tube, which was then passed through a $53 \mu \mathrm{m}$ mesh sieve, since the tank hatch could not be opened. After collection, ballast water samples were preserved with $95 \%$ ethanol and sent for taxonomic identification.

Zooplankton and zoobenthos were collected from 11 Saint Lawrence River ports on three occasions between September 2009 and September 2010, and from four Great Lakes ports in August 2010. In total, we collected 88 zooplankton and 42 benthic samples. Details regarding sampling site locations and characteristics are provided in Fig. 1 and Table 1. Zooplankton sampling in ports was conducted from a boat using triplicate vertical plankton net tows of 41 and $500 \mu \mathrm{m}$ mesh. Upon collection, samples were rinsed from the cod-end of the net into a 41 or $500 \mu \mathrm{m}$ sieve corresponding to the net's mesh size. Samples were rinsed while still in the sieve with $95 \%$ ethanol to remove fine sediment before being preserved with $95 \%$ ethanol. We collected benthic invertebrates using either a sled dredge (rocky substrate) or ponar grab (sand or mud bottom). Sled dredge samples were collected by gently dragging the net along the bottom for approximately 5 min. Ponar grab sampling involved two to three grab samples collected from different points, which were subsequently combined into a single sample. After retrieval, benthic samples were transferred into a sieving bucket with $1 \mathrm{~mm}$ mesh screen bottom and washed with port water to remove sediment, clay, and organic matter. We examined macrofauna for viability (e.g., movement) with the naked eye before samples were washed into $1 \mathrm{~L}$ jars, preserved with $95 \%$ ethanol, and transported to the laboratory for analysis. Four limnological parameters-temperature, salinity, conductivity and dissolved oxygen-were recorded during each port sampling event using a handheld YSI instrument (Table 1).

Animals in port plankton samples were examined under a dissecting microscope at $0.63-5 \times$ magnification. We split dense samples into fractions using a Folsom splitter, and each fraction thereafter examined. Animals were counted and separated into broad taxonomic groups (e.g., cladocerans, rotifers) and a maximum of 30 individuals for each group was collected for detailed taxonomic identification (Humphrey 2008). Benthic samples were rinsed with $95 \%$ ethanol into $1 \mathrm{~mm}, 500$ and $45 \mu \mathrm{m}$ stacked sieves, with animals concentrated on each sieve subsequently counted and sorted into taxonomic groups. The $1 \mathrm{~mm}$ fraction was examined by eye, while the 500 and

Table 1 Recorded longitude, latitude, mean temperature, mean conductivity, dissolved oxygen, and mean salinity for Saint Lawrence River ports (September 2009, July and September 2010) and Great Lakes ports (August 2010)

\begin{tabular}{|c|c|c|c|c|c|c|}
\hline Port & $\begin{array}{l}\text { Longitude } \\
\left({ }^{\circ} \mathrm{W}\right)\end{array}$ & $\begin{array}{l}\text { Latitude } \\
\left({ }^{\circ} \mathrm{N}\right)\end{array}$ & $\begin{array}{l}\text { Temperature } \\
( \pm \mathrm{SE})\left({ }^{\circ} \mathrm{C}\right)\end{array}$ & $\begin{array}{l}\text { Conductivity } \\
( \pm \mathrm{SE})(\mu \mathrm{S})\end{array}$ & $\begin{array}{l}\text { Dissolved oxygen } \\
( \pm \mathrm{SE})(\%)\end{array}$ & $\begin{array}{l}\text { Salinity } \\
( \pm \mathrm{SE})(\mathrm{ppt})\end{array}$ \\
\hline Baie Comeau & 68.14 & 49.25 & $3.6 \pm 0.9$ & $34 \pm 1$ & $12 \pm 1$ & $32.4 \pm 0.9$ \\
\hline Contrecoeur & 73.28 & 45.83 & $24.0 \pm 0.3$ & $307 \pm 1$ & $8 \pm 1$ & $0.1 \pm 0.0$ \\
\hline Côte Ste Catherine & 73.59 & 45.41 & $23.1 \pm 0.0$ & $304 \pm 3$ & $8 \pm 0$ & $0.1 \pm 0.0$ \\
\hline Duluth & 92.11 & 46.77 & 22.3 & 263 & 9 & 0.1 \\
\hline Hamilton & 79.80 & 43.28 & 25.3 & 586 & 8 & 0.3 \\
\hline Johnstown Harbour & 75.47 & 44.74 & $20.8 \pm 0.4$ & $302 \pm 2$ & $8 \pm 0$ & $0.2 \pm 0.0$ \\
\hline Montréal & 73.51 & 45.58 & $24.0 \pm 0.7$ & $307 \pm 2$ & $9 \pm 0$ & $0.1 \pm 0.0$ \\
\hline Port Cartier & 66.78 & 50.03 & $10.9 \pm 0.4$ & $35 \pm 1$ & $10 \pm 0$ & $31.1 \pm 0.5$ \\
\hline Quebec City & 71.20 & 46.82 & $21.0 \pm 0.6$ & $280 \pm 3$ & $8 \pm 0$ & $0.1 \pm 0.0$ \\
\hline Sarnia & 82.45 & 42.93 & 23.3 & 224 & 8 & 0.1 \\
\hline Sept Îles & 66.37 & 50.19 & $13.2 \pm 0.3$ & $35 \pm 1$ & $9 \pm 0$ & $29.5 \pm 0.5$ \\
\hline Sorel & 73.14 & 46.05 & $24.7 \pm 0.4$ & $196 \pm 1$ & $7 \pm 0$ & $0.1 \pm 0.0$ \\
\hline Thunder Bay & 89.22 & 48.41 & 20.4 & 105 & 9 & 0.1 \\
\hline Tracy & 73.12 & 46.05 & $23.6 \pm 0.1$ & $320 \pm 5$ & $8 \pm 0$ & $0.1 \pm 0.0$ \\
\hline Trois Rivières & 72.55 & 46.33 & $24.3 \pm 0.3$ & $293 \pm 3$ & $8 \pm 0$ & $0.1 \pm 0.0$ \\
\hline
\end{tabular}


$45 \mu \mathrm{m}$ fractions were examined under a dissecting microscope $(0.63-5 \times$ magnification). As with zooplankton samples, we examined a maximum of 30 individuals of each broad group for detailed taxonomic identification.

Ballast water and port samples were sent out for expert identification (EcoAnalysts INC., Moscow, ID and Biologica Environmental Services Ltd., Victoria, $\mathrm{BC}$, respectively), except for port rotifers. Rotifers were identified according to Koste (1978) and Stemberger (1979), and were verified by Dr. Ian Duggan (University of Waikato). The majority of port rotifers were identified only to genus level because animals were distorted owing to preservation in ethanol.

Data analysis

To assess the introduction potential posed by Saint Lawrence River ballast, we examined both the potential for arrival and potential for survival at recipient ports. We recorded the number of individuals per species and species richness for ballast water and port samples. A variety of freshwater and marine taxa were found in port and ballast water samples. Identified species were characterized as native to the Great Lakes, NIS not reported from the Great Lakes, NIS already established in the Great Lakes, or cryptic species (Stemberger 1979; Balcer et al. 1984; Kelly et al. 2009; USGS 2009). NIS not reported from the Great Lakes were further researched, primarily using the World Register of Marine Species and the Web of Science, to determine species' distribution and evaluate potential for survival in the freshwater Great Lakes. We compared the abundance of NIS not reported from the Great Lakes in our Saint Lawrence River ballast samples against similar data for vessels with foreign exchanged ballast water (Bailey et al. 2011a) to evaluate the relative importance of this pathway. The nonparametric Mann-Whitney U test with $\alpha=0.05$ was used due to the skewed data distribution (many 'zero' values)(JMP ${ }^{\circledR}$ Version 10 statistical software; SAS Institute Inc. 2012).

Biological similarity of Saint Lawrence RiverGreat Lakes port-pairs was determined by comparing the community of species found in samples from individual high and medium risk Saint Lawrence River ports to that in the top two corresponding Great Lakes recipient ports. Biological similarity was calculated using species presence/absence data and
Sørensen's similarity index (SSI), using SPADE software (Sørensen 1948; Chao and Shen 2006):

$S S I=\frac{2 D_{12}}{D_{1}+D_{2}}$

where $D_{1}$ is the number of observed species in sample 1 , $D_{2}$ is the number of species observed in sample 2, and $D_{12}$ is the number of observed species in the two samples (Chao and Shen 2006). Index values ranges from zerofor communities that have no species overlap-to one, for communities that have all species in common.

\section{Results}

Total zooplankton abundance in ballast water ranged from 5.8 to $20.2 \times 10^{5}$ individuals $\mathrm{m}^{-3}$, with a median abundance of $1.4 \times 10^{4}$ individuals $\mathrm{m}^{-3}$ (see Online Resource 1). We identified 78 distinct zooplankton taxa from ballast water samples, ranging from 4 to 26 species per sample (Online Resource 2); thirteen NIS not reported from the Great Lakes were identified from six freshwater and nine marine ballast samples. We calculated total and mean abundance of each NIS not present in the Great Lakes across all ballast water samples as a measure of the arrival potential each species exerts on the Great Lakes (Online Resource 3). Both abundance and richness of these NIS were significantly higher in marine (median $6.7 \times 10^{3}$ individuals $\mathrm{m}^{-3}$ when present; 5 NIS) than freshwater samples (median 3.3 individuals $\mathrm{m}^{-3}$ when present; 1 NIS) (Mann-Whitney U test; $p<0.001$ ). The abundance of NIS not reported from the Great Lakes in Saint Lawrence River ballast water was also significantly greater than that sampled from foreign exchanged ballast water (median 850 individuals $\mathrm{m}^{-3}$; Briski et al. 2012b) (Mann-Whitney U test; $p<0.01$ ).

Rotifers were the most abundant $(69 \%$ total abundance) and diverse (40 species; $54 \%$ total richness) group sampled; however, all rotifer species were already present in the Great Lakes (Online Resource 2). Bivalve veligers were the second-most abundant group (23\% total abundance), followed by copepods (6\%), and cladocerans (2\%). Amphipods, cirripeds and decapods all represented $<1 \%$ of zooplankton abundance in ballast samples. Copepods were the secondmost diverse group with 15 species, including eight species not reported from the Great Lakes (Acartia hudsonica, Centropages hamatus, Epischura 
nordenskiøldi, Temora longicornis, Tortanus discaudatus, Oithona similis, Coullana canadensis and Microsetella norvegica) and one NIS already established (Schizopera borutskyi). We identified eleven cladoceran species, including one species not reported from the Great Lakes (Evadne nordmanni) and one NIS already established in the Great Lakes (Eubosmina coregoni). We identified three bivalves, including the species c.f. Mytilus edulis not reported from the Great Lakes, and the two dreissenid mussels already established. The two decapod taxa (c.f. Cancerirroratus and c.f. Uca sp.) found in ballast from Port Cartier are both marine species not reported from the Great Lakes. The single cirriped species (c.f. Balanus sp.) is a marine species not reported from the Great Lakes while the single amphipod sampled is a NIS already established (Echinogammarus ischnus). While the majority of potential NIS not recorded from the Great Lakes are marine species that were exclusively collected from marine ballast samples, $O$. similis is a euryhaline species reported from freshwater environments, that we also sampled in freshwater ballast from Montreal (Table 2). The marine E. nordenskiфldi and brackish $M$. norvegica are not reported from fresh water globally, but still exhibit potential for survival in the Great Lakes as they were sampled in freshwater ballast sourced from Montreal and Sorel (Table 2).

During the Saint Lawrence River port surveys, we identified 67 distinct taxa from freshwater ports,

Table 2 List of potential NIS sampled from Saint Lawrence River freshwater ballast and port samples, respectively

\begin{tabular}{|c|c|c|c|c|c|c|}
\hline & $\mathrm{JH}$ & M & $\mathrm{T}$ & $\mathrm{S}$ & TR & QC \\
\hline \multicolumn{7}{|c|}{ Potential NIS in ballast samples } \\
\hline $\begin{array}{l}\text { Epischura } \\
\text { nordenskiøldi }\end{array}$ & & & & & & $\mathrm{x}$ \\
\hline Oithona similis & & $\mathrm{x}$ & & & & \\
\hline Microsetella norvegica & & $\mathrm{X}$ & $\mathrm{x}$ & $\mathrm{x}$ & & \\
\hline \multicolumn{7}{|c|}{ Potential NIS in port samples } \\
\hline Gammarus oceanicus & & & & $\mathrm{x}$ & $\mathrm{x}$ & \\
\hline Gammarus palustris & & & $\mathrm{x}$ & & $\mathrm{x}$ & \\
\hline $\begin{array}{l}\text { Chaetogaster } \\
\text { diaphanus }\end{array}$ & $\mathrm{x}$ & $\mathrm{x}$ & $\mathrm{x}$ & $\mathrm{x}$ & & \\
\hline Stylaria lacustris & & & $\mathrm{x}$ & & $\mathrm{x}$ & $\mathrm{x}$ \\
\hline
\end{tabular}

Source port of ballast water is indicated. Ports are: $J H$ Johnstown Harbour, $M$ Montreal, $T$ Tracy, $S$ Sorel, $T R$ Trois Rivières, $Q C$ Québec City; no potential NIS were reported from Côte Ste Catherine or Contrecoeur including four NIS not reported from the Great Lakes (Online Resource 4; Table 2). Rotifers were the most abundant group, accounting for $46 \%$ of total invertebrate abundance. Bivalves (veligers and adults) were the second-most abundant taxon (22\%), followed by cladocerans $(20 \%)$ and 11 other rare (12\% total) taxa (amphipods, caddisflies, copepods, dipterans, dragonflies, gastropods, mayflies, mites, mysids, oligochaetes and polychaetes). Oligochaetes were the most diverse group in freshwater Saint Lawrence River ports, with 15 species (including two not reported from the Great Lakes, Chaetogaster diaphanus and Stylaria lacustris; and one established Great Lakes NIS, Ripistes parasita) followed by cladocerans (12 species, with two Great Lakes NIS, Bythotrephes longimanus and $\mathrm{Eu}$ bosmina coregoni), rotifers (11 species), dipterans (11 species), bivalves (four species including Great Lakes NIS Dreissena polymorpha and Dreissena rostriformis bugensis), and amphipods (three species, including Gammarus oceanicus and Gammarus palustris which are not reported from the Great Lakes). Other groups included mites (three species), copepods and mayflies (two species each), and caddisflies, dragonflies, gastropods, mysids and polychaetes with one species each.

We identified fifty-two taxa from marine Saint Lawrence River ports, including 23 species not reported from the Great Lakes (Online Resource 4). Rotifers and polychaetes dominated invertebrate communities, representing 50 and $25 \%$ of total abundance, respectively. Relative abundance of the remaining 12 major taxonomic groups was much lower, collectively accounting for $25 \%$ of zooplankton abundance. Four taxa (polychaetes, amphipods, bivalves and dipterans) contributed most to species diversity $(31,19,12$ and $12 \%$, respectively), whereas the other ten taxa collectively contributed only $26 \%$. Only one Great Lakes established NIS, Dreissena polymorpha, was found in marine port samples. Taxa not reported from the Great Lakes include amphipods (Pontogeneia inermis, Anonyx sarsi, Gammarus oceanicus, Caprella linearis, Tmetonyx cicada, Calliopius laeviusculus, Monocorophium acherusicum, Monoculodes tuberculatus and Orchomenella groenlandica), bivalves (Macoma calcarea), cirripeds (Balanus sp.), cladocerans (Evadne sp.), cumaceans (Diastylis rathkei), decapods (Eualus gaimardi and Cancer irroratus), echinoderms (Ophiura robusta) and polychaetes (Goniada maculata, Capitella capitata complex, Harmothoe extenuata, Gattyana 
cirrhosa, Nephtys cornuta, Pectinaria granulata and Harmothoe imbricata).

We identified thirty-six species from samples collected at ports on the Great Lakes (Online Resource 5). Cladocerans and rotifers were most abundant, accounting for 37 and $34 \%$ of total invertebrate abundance, respectively. Eight other taxa collectively accounted for $29 \%$ of total individuals surveyed. Cladocerans and oligochaetes exhibited greatest diversity with 11 and nine species, respectively, followed by rotifers (eight species) and the remaining five taxa (11 species). Two established cladoceran (Bythotrephes longimanus and Eubosmina coregoni) and dreissenid (Dreissena polymorpha and Dreissena rostriformis bugensis) NIS were recorded in port samples.

Sørensen's similarity index values for all high and medium risk donor Saint Lawrence River ports and their respective top Great Lakes recipient ports ranged from 0.07 (Port Cartier-Thunder Bay) to 0.53 (TracyThunder Bay), indicating that none of the Saint Lawrence River-Great Lakes port-pairs are highly similar in community composition.

\section{Discussion}

This is the first study to examine the potential for introduction of new NIS through domestic ballast water transported from the Saint Lawrence River to the Great Lakes. The abundance of NIS not yet present in the Great Lakes was significantly higher for ships with marine versus freshwater ballast, however no new freshwater NIS not reported from the Great Lakes were found in any Saint Lawrence River ballast water or port sample. We did, however, record 33 marine species and two brackish water taxa not reported from the Great Lakes, seven of which were collected from freshwater samples. In addition, we recorded the euryhaline copepod $O$. similis from multiple ballast water samples. We observed only minimal overlap in community composition of ballast and port samples (12 shared taxa), indicating that additional species might be detected with increased sample effort (see also Adebayo 2012). The list of potential NIS reported in our port and ballast water samples is only an indication of risk, as our sampling was limited in both spatial and temporal coverage, and we were unable to identify all organisms to species level, making our species list non-exhaustive. Other studies have shown that the Saint Lawrence River is inhabited by at least one freshwater invertebrate NIS (spiny cheek crayfish, Orconectes limosus) and two freshwater fish NIS (the tench Tinca tinca and cutthroat trout Oncorhynchus clarki) that are not reported from the Great Lakes, thus there is at least some potential for freshwater NIS to be moved from the Saint Lawrence River to the Great Lakes (de Lafontaine and Costan 2002).

Given that we observed seven marine species from freshwater ballast or port samples, a potential exists for the establishment of marine Saint Lawrence River taxa at ports on the Great Lakes. Although invasion potential of marine taxa into freshwater habitats is generally considered low, the establishment risk of such species in the Great Lakes should not be discounted (Drake and Lodge 2007; Briski et al. 2012a). While not common, some invertebrates are able to successfully transition from marine to freshwater habitats (Lee 1999). For example, the marine copepod Eurytemora affinis had achieved multiple, independent freshwater transitions with strong selection pressure for freshwater tolerance before successful invasion in the Great Lakes (Lee 1999; Lee et al. 2003). Similarly, the marine amphipod Gammarus tigrinus has several independent lineages that have invaded freshwater habitats, with the introduced population in the Great Lakes likely the product of intense selection following ballast-mediated introduction (Kelly et al. 2006).

Our results indicate that four ports (Montreal, Sorel, Tracy and Trois Rivières) on the Saint Lawrence River pose the highest risk for ballast-mediated transfer of species to the Great Lakes. These four ports are also important recipients for ballast water discharges, receiving a combined annual total of 191,692 and 424,571 tonnes of unexchanged coastal and international ballast, respectively, thus underscoring that they could also serve as intermediate stages of 'stepping stone' or secondary invasions to the Great Lakes (Floerl et al. 2009; Bailey et al. 2011b). The presence of established NIS in $90 \%$ of our ballast water samples supports the hypothesis that domestic vessels facilitate secondary invasions of NIS within the Great Lakes. Furthermore, translocation of established NIS can introduce novel genotypes to populations already established in the Great Lakes or serve to augment populations and reduce demographic stochasticity (Kelly et al. 2006). Some authors have argued that such genetic enhancements through admixture may increase the invasiveness of NIS (e.g. Kelly et al. 2006; Handley et al. 2011). 
The mean abundance of zooplankton in Saint Lawrence River ballast water was significantly greater than that documented in a similar study of foreign exchanged ballast water bound for the Great Lakes (Bailey et al. 2011a; Briski et al. 2012b), indicating that domestic ballast water may currently be a more important vector for NIS in the Great Lakes than exchanged ballast discharged by transoceanic ships. Arguments that the Great Lakes-St. Lawrence River are a single contiguous ecosystem that should be managed as "common waters" are not supported by our analysis of biological similarity between source-recipient port-pairs. Finally, we provide evidence that species native to the St. Lawrence River, including some marine taxa, pose a risk for survival and future invasion of the Great Lakes.

Acknowledgments We thank the Canadian Shipowners Association, and its member companies and vessel crews, for participating in this research and the Saint Lawrence Seaway Management Corporation for allowing access to vessels. We thank Sandra Ellis, Jocelyn Gerlofsma, Phil Jenkins and Colin van Overdijk for participating in sample collection, Dr. Ian Duggan, EcoAnalysts, Inc. and Biologica Environmental Services Ltd. for taxonomic analyses, and Dr. Nick Gotelli for biodiversity assessment advice. We are grateful to two anonymous reviewers for helpful comments on the manuscript. This study was supported by NSERC Discovery grants to SAB and HJM, Discovery Accelerator Supplement to HJM, and by the Ontario Ministry of Natural Resources, Fisheries and Oceans Canada and Transport Canada.

\section{References}

Adebayo AA (2012) Domestic 'laker' ships as a potential pathway of nonindigenous species in the Great Lakes. M.Sc. thesis, University of Windsor

Bailey SA, Duggan IC, Nandakumar K, MacIsaac HJ (2007) Sediments in ships: biota as biological contaminants. Aquat Ecosyst Health Manag 10:93-100

Bailey SA, Deneau MG, Jean LJ, Wiley CJ, Leung B, MacIsaac HJ (2011a) Evaluating efficacy of an environmental policy to prevent biological invasions. Environ Sci Technol 45:2554-2561

Bailey SA, Chan F, Ellis SM, Bronnenhuber JE, Bradie JN, Simard N (2011b) Risk assessment for ship-mediated introductions of aquatic nonindigenous species to the Great Lakes and freshwater St. Lawrence River. DFO Can Sci Advis Sec Res Doc 2011/104. vi + 224 p

Balcer MD, Korda NL, Dodson SI (1984) Zooplankton of the Great Lakes: a guide to the identification and ecology of the common crustacean species. The University of Wisconsin Press, Madison

Briski E, Ghabooli S, Bailey SA, MacIsaac HJ (2012a) Invasion risk posed by macro invertebrates transported in ships' ballast tanks. Biol Invasions 14:1843-1850
Briski E, Wiley CJ, Bailey SA (2012b) Role of domestic shipping in the introduction or secondary spread of nonindigenous species: biological invasions within the Laurentian Great Lakes. J Appl Ecol 49:1124-1130

Briski E, Bailey SA, Casas-Monroy O, DiBacco C, Kaczmarska I, Lawrence JE, Leichsenring J, Levings C, MacGillivary ML, McKindsey CW, Nasmith LE, Parenteau M, Piercey GE, Rivkin RB, Rochon A, Roy S, Simard N, Sun B, Villac MC, Way C, Weise AM, MacIsaac HJ (2013) Ballast water management alters but does not eliminate the threat of invasions from shipping. Limnol Oceanogr 58:1361-1372

Chao A, Shen TJ (2006) SPADE version 3.1. Available from: http://chao.stat.nthu.edu.tw

David M, Gollasch S, Pavliha M (2013) Global ballast water management and the "same location" concept: a clear term or a clear issue? Ecol Appl 23:331-338

de Lafontaine Y, Costan G (2002) Introduction and transfer of alien aquatic species in the Great Lakes-St. Lawrence River drainage basin. In: Claudi R, Nantel P, Muckle-Jeffs E (eds) Alien invaders in Canada's waters, wetlands, and forests. Natural Resources Canada, Canadian Forestry Service, Science Branch, Ontario, pp 73-92

Drake JM, Lodge DM (2007) Rate of species introductions in the Great Lakes via ships' ballast water and sediments. Can J Fish Aquat Sci 64:530-538

Floerl O, Inglis GJ, Dey K, Smith A (2009) The importance of transport hubs in stepping-stone invasions. J Appl Ecol 46:37-45

Government of Canada (2006) Ballast water control and management regulations. Canada Gazette 140:13

Handley LJL, Estoup A, Evans DM, Thomas CE, Lombaert E, Facon B, Aebi A, Roy HE (2011) Ecological genetics of invasive alien species. Biocontrol 56:409-428

Hulme PE (2009) Trade, transport and trouble: managing invasive species pathways in an era of globalization. J Appl Ecol 46:10-18

Humphrey DB (2008) Characterizing ballast water as a vector for nonindigenous zooplankton transport. M.Sc. thesis, University of British Columbia

Kelly DM, Muirhead JR, Heath DD, MacIsaac HJ (2006) Contrasting patterns in genetic diversity following multiple invasions of fresh and brackish waters. Mol Ecol 15:3641-3653

Kelly DW, Lamberti GA, MacIsaac HJ (2009) The Laurentian Great Lakes as a case study of biological invasions. In: Keller RP, Lodge DM, Lewis MA, Shogren JF (eds) Bioeconomics of invasive species: integrating ecology, economics, policy and management. Oxford University Press, Oxford, pp 205-225

Koste W (1978) Rotatoria. Die Radertiere Mitteleuropas begrundel von Max Voigt. Monogononta. Gebruder Borntraeger, Berlin, Stuttgart

Lawrence DJ, Cordell JR (2010) Relative contributions of domestic and foreign sourced ballast water to propagule pressure in Puget Sound, Washington, USA. Biol Conserv 143:700-709

Lee CE (1999) Causes and consequences of recent freshwater invasions by saltwater animals. Trends Ecol Evol 14:284-288

Lee CE, Remfert JL, Gelembiuk GW (2003) Evolution of physiological tolerance and performance during freshwater invasion events. Integr Comp Biol 43:439-449 
Lodge DM, Williams S, MacIsaac HJ, Hayes KR, Leung B, Reichard S, Mack RN, Moyle PB, Smith M, Andow DA, Carlton JT, McMichael A (2006) Biological invasions: recommendations for US policy and management. Ecol Appl 16:2035-2054

Mack RN, Simberloff D, Lonsdale WM, Evans H, Clout M, Bazzaz F (2000) Biotic invasions: causes, epidemiology, global consequences, and control. Ecol Appl 10:689-710

Minchin D, Gollasch S (2003) Fouling and ships' hulls: how changing circumstances and spawning events may result in spread of exotic species. Biofouling 19:111-122

Ricciardi A (2006) Patterns of invasion in the Laurentian Great Lakes in relation to changes in vector activity. Divers Distrib 12:425-433

Ricciardi A, MacIsaac HJ (2000) Recent mass invasions of the North American Great Lakes by Ponto-Caspian species. Trends Ecol Evol 15:62-65

Ruiz GM, Carlton JT, Grosholz ED, Hines AH (1997) Global invasions of marine and estuarine habitats by non-indigenous species: mechanisms, extent, and consequences. Am Zool 37:621-632

Rup MP, Bailey SA, Wiley CJ, Minton MS, Miller AW, Ruiz GM, MacIsaac HJ (2010) Domestic ballast operations on the Great Lakes: potential importance of Lakers as a vector for introduction and spread of nonindigenous species. Can J Fish Aquat Sci 67:256-268
Simkanin C, Davidson I, Falkner M, Sytsma M, Ruiz G (2009) Intra-coastal ballast water flux and the potential for secondary spread of non-native species on the US West Coast. Mar Poll Bull 58:366-374

Sørensen T (1948) A method of establishing groups of equal amplitude in plant sociology based on similarity of species content and its application to analyses of the vegetation on Danish commons. K Dan Vidensk Selsk Biol Skr 5:1-34

Stemberger RS (1979) A guide to rotifers of the Laurentian Great Lakes. US. Environmental Protection Agency, Washington, DC. EPA/600/4-79/021 (NTIS PB80101280)

Sylvester F, MacIsaac HJ (2010) Is vessel hull fouling an invasion threat to the Great Lakes? Divers Distrib 16:132-143

USCG (United States Coast Guard) (1998) Ballast water management for vessels entering the Great Lakes. Code of Federal Regulations, 33-CFR Part 151.1510

USGS (United States Geological Survey) (2009) Nonindigenous aquatic species database. Available from: http://nas.er. usgs.gov

Vincent W, Dodson JJ (1999) The St. Lawrence R., CanadaUSA: the need for an ecosystem level understanding of large rivers. Japanese J Limnol 60:29-45

Work TT, McCullough DG, Cavey JF, Komsa R (2005) Arrival rate of nonindigenous insect species into the United States through foreign trade. Biol Invasions 7:323-332 